\title{
Strawberry pelargonidin glycosides are excreted in urine as intact glycosides and glucuronidated pelargonidin derivatives in rats
}

\author{
Catherine Felgines ${ }^{1}$, Odile Texier ${ }^{1}$, Catherine Besson ${ }^{2}$, Bernard Lyan $^{2}$, Jean-Louis Lamaison ${ }^{1}$ \\ and Augustin Scalbert ${ }^{2}$ \\ ${ }^{1}$ Université Clermont 1, UFR Pharmacie, Laboratoire de Pharmacognosie, 28 Place Henri Dunant, \\ BP 38, F-63001 Clermont-Ferrand Cedex 1, France \\ ${ }^{2}$ Institut National de la Recherche Agronomique, Unité de Nutrition Humaine, Clermont-Ferrand/Theix, F-63122, France \\ (Received 17 January 2007 - Revised 23 March 2007 - Accepted 27 April 2007)
}

\begin{abstract}
Anthocyanins are natural dietary pigments with a wide array of biological properties that are possibly involved in the prevention of various diseases. These properties depend on their absorption and metabolism in the body. In the present study we first examined the gastric and intestinal absorption of pelargonidin 3-glucoside (Pg 3-glc) using rat in situ models. A high proportion of Pg 3-glc was rapidly absorbed from both the stomach $(23 \%)$ and small intestine $(24 \%)$. Its metabolism was further studied by feeding rats during $8 \mathrm{~d}$ with a diet enriched in freeze-dried strawberries. Only low amounts of total anthocyanins were recovered in $24 \mathrm{~h}$ urine (0.163 (SEM 0.013) \% of ingested anthocyanins; $n$ 8). Strawberry anthocyanins were analysed in urine by HPLC-electrospray ionisation-tandem MS. Similar proportions of intact glycosides (about $53 \%$ ) and glucuronidated metabolites (about 47\%) were found. Pg 3-glc was thus glucuronidated to a larger extent than cyanidin 3-glucoside. These results highlight the influence of the aglycone structure on anthocyanin metabolism.
\end{abstract}

Absorption: Anthocyanins: Metabolism: Pelargonidin: Strawberries

Anthocyanins are natural dietary pigments widely distributed in fruits and especially in berries ${ }^{1}$. Their average daily intake was estimated for a long time at about $200 \mathrm{mg} / \mathrm{d}$ in the $\mathrm{USA}^{2}$, but much lower intake values were determined by others $(6.6 \mathrm{mg} / \mathrm{d}$ in Germany and $12.5 \mathrm{mg} / \mathrm{d}$ in the USA $)^{3,4}$. However, intakes higher than $100 \mathrm{mg} / \mathrm{d}$ could be easily achieved with the regular consumption of red fruits or berries. Also the contribution of natural food colorants rich in anthocyanins to the total intake of anthocyanins has never been estimated. It may significantly contribute to the total anthocyanin dietary intake.

Anthocyanins are implicated in many biological activities that may impact positively on health ${ }^{5,6}$. They may reduce the risk of CHD, exert anticarcinogenic and neuroprotective activities, reduce inflammatory insult and modulate the immune response ${ }^{7-11}$. These actions might be mediated by their antioxidant activities $5,12,13$.

In view of these multiple biological activities, the bioavailability and metabolism of anthocyanins are important issues. We observed in a previous human study that the urinary excretion of anthocyanin metabolites differs according to the anthocyanins ingested ${ }^{14,15}$. This excretion was about 10 -fold lower after consumption of blackberries (cyanidin 3-glucoside; Cy 3-glc) than after ingestion of strawberries (pelargonidin 3-glucoside; Pg 3-glc) using the same study design. So, it seems that the metabolic fate of anthocyanins may differ according to their aglycone structure. The reason for this difference between Pg 3-glc and Cy 3-glc urinary excretion has not been elucidated to date. It may be linked to different metabolic pathways and/or from different absorption rates. Thus, the aim of the present study was to study the metabolism of strawberry anthocyanins (Pg 3-glc) and to determine Pg 3-glc absorption along the digestive tract in the rat. For this purpose, the urinary excretion and metabolism of strawberry anthocyanins were evaluated in rats fed a diet enriched with freeze-dried strawberries. The gastric and intestinal absorption of Pg 3-glc was also studied using in situ rat models.

\section{Materials and methods}

Chemicals

$\mathrm{Pg}$ 3-glc and $\mathrm{Cy}$ 3-glc were purchased from Extrasynthèse (Genay, France).

\section{Animals and diets}

'Adapted rat' study. Eight male Wistar rats (Iffa-Credo, L'Arbresle, France) weighing approximately $200 \mathrm{~g}$ were housed two per cage in temperature-controlled rooms

Abbreviations: Cy 3-glc, cyanidin 3-glucoside; HPLC-ESI-MS/MS, HPLC-electrospray ionisation-tandem MS; Pg, pelargonidin; Pg 3-glc, pelargonidin 3-glucoside; Pg 3-malglc, pelargonidin 3-malonylglucoside.

*Corresponding author: Dr C. Felgines, fax +334732828 49, email catherine.felgines@u-clermont1.fr 
$\left(22^{\circ} \mathrm{C}\right)$, with a controlled dark period from 08.00 to 20.00 hours and access to food from 08.00 to 16.00 hours. They were fed a semi-purified control diet $(755 \mathrm{~g}$ wheat starch, $150 \mathrm{~g}$ casein, $50 \mathrm{~g}$ groundnut oil, $35 \mathrm{~g}$ AIN-93M mineral mixture, $10 \mathrm{~g}$ AIN-76A vitamin mixture per $\mathrm{kg}$ ) for $6 \mathrm{~d}^{16}$. They were then individually housed in metabolism cages fitted with urine and faeces separators and received the control diet supplemented with strawberry powder $(200 \mathrm{~g} / \mathrm{kg}$ diet $)$ for $8 \mathrm{~d}$. Rats ate about $19.3 \mathrm{~g}$ diet/d, i.e. about $3.85 \mathrm{~g}$ strawberry powder/d. Strawberry powder resulted from frozen strawberries that were lyophilised, pulverised and then sieved to eliminate achenes. To quantify anthocyanins administered to rats, strawberry powder $(0.5 \mathrm{~g})$ was treated for 30 min under agitation with $95 \mathrm{ml}$ methanol. After filtration, the volume of solution was adjusted to $100 \mathrm{ml}$, and this solution was 5 -fold-diluted with $0.12 \mathrm{M}-\mathrm{HCl}$ before HPLC analysis $(20 \mu \mathrm{l})$ as described later.

In situ experiments. Twelve male Wistar rats (Iffa-Credo) weighing approximately $200 \mathrm{~g}$ were housed two per cage in temperature-controlled rooms $\left(22^{\circ} \mathrm{C}\right)$, with a controlled dark period from 20.00 to 08.00 hours and access to food from 16.00 to 08.00 hours. They were fed the semi-purified control diet for 2 weeks.

All animals were maintained and handled according to the recommendations of the Institutional Ethics Committee (INRA), in accordance with French decree no. 87-848.

\section{Sampling procedure during 'adapted rat' study}

Rats were killed at $3 \mathrm{~h}$ after the beginning of the last experimental meal (i.e. at 11.00 hours) after being anaesthetised with sodium pentobarbital $(40 \mathrm{mg} / \mathrm{kg}$ body weight). Blood was withdrawn from the abdominal aorta into heparinised tubes and urine present in the bladder was collected. Plasma and urine samples were rapidly acidified with $240 \mathrm{mM}-\mathrm{HCl}$. The day before killing, urine was collected over $24 \mathrm{~h}$ in tubes containing $1 \mathrm{ml} 3 \mathrm{M}-\mathrm{HCl}$ and exact food consumption was checked. Collection of urine on $\mathrm{HCl}$ allowed regeneration of the coloured structure of anthocyanins as urine fell into the tubes and thus increased their stability. Caecal contents were drained by finger pressure into microfuge tubes. All samples were rapidly frozen and stored at $-20^{\circ} \mathrm{C}$ until analysis.

\section{Anthocyanin administration during in situ experiments}

Rats fasted for $24 \mathrm{~h}$ were anaesthetised with sodium pentobarbital $(40 \mathrm{mg} / \mathrm{kg}$ body weight) and kept alive under anaesthesia throughout the experiments.

In situ gastric administration. After cannulation of the bile duct, the pylorus was ligated and a physiological buffer was injected into the stomach across the cardia. This sphincter was ligated to prevent any gastro-oesophageal reflux. The stomach was filled in situ with $5 \mathrm{ml}$ of a Pg 3-glc solution $(12 \mu \mathrm{M})$ in a buffer specially developed to mimic the osmotic and $\mathrm{pH}$ conditions found in the stomach during a meal. This buffer ( $\mathrm{pH} 3$ ) contained $\mathrm{KH}_{2} \mathrm{PO}_{4}(7.5 \mathrm{mM}), \mathrm{NaCl}(50 \mathrm{~mm})$, $\mathrm{KCl}(50 \mathrm{mM}), \mathrm{CaCl}_{2}(2 \mathrm{mM})$, acetic acid $(25 \mathrm{mM})$, lactic acid $(25 \mathrm{mM}), \mathrm{MgSO}_{4}(1 \mathrm{mM})$ and polyethylene glycol 6000 (5 g/ 1) and was maintained at $37^{\circ} \mathrm{C}^{17}$. At $30 \mathrm{~min}$ after administration, the stomach contents were collected and blood samples were withdrawn from the abdominal aorta into heparinised tubes. Bile was collected throughout the $30 \mathrm{~min}$ of the experiment. Urine present in the bladder was also collected. Plasma, bile and urine samples were acidified with $240 \mathrm{~mm}-\mathrm{HCl}$ while stomach contents were acidified with $40 \mathrm{~mm}-\mathrm{HCl}$. All samples were stored at $-20^{\circ} \mathrm{C}$ until analysis. We have controlled that Pg 3-glc was stable under the experimental conditions, i.e. incubated for $30 \mathrm{~min}$ at $37^{\circ} \mathrm{C}$ in the gastric buffer ( $\mathrm{pH} 3$ ).

In situ intestinal perfusion. After cannulation of the bile duct, a perfusion of the jejuno-ileal segment of the intestine (from $5 \mathrm{~cm}$ distal from the duodeno-jejunal flexure up to the ileo-caecal valve) was prepared by installing cannulas at each extremity. This segment was continuously perfused in situ for $45 \mathrm{~min}$ at a flow rate of $0.75 \mathrm{ml} / \mathrm{min}$ with a buffer containing $\mathrm{KH}_{2} \mathrm{PO}_{4}(5 \mathrm{~mm}), \mathrm{K}_{2} \mathrm{HPO}_{4}(2 \cdot 5 \mathrm{~mm}), \mathrm{NaHCO}_{3}(5 \mathrm{~mm})$, $\mathrm{NaCl}(50 \mathrm{~mm}), \mathrm{KCl}(40 \mathrm{~mm}), \mathrm{CaCl}_{2}(2 \mathrm{~mm}), \mathrm{MgSO}_{4}(1 \mathrm{~mm})$, $\mathrm{K}_{3} \mathrm{C}_{6} \mathrm{H}_{5} \mathrm{O}_{7}(10 \mathrm{mM})$, glucose $(12 \mathrm{mM})$, glutamine $(2 \mathrm{mM})$ and taurocholic acid (1 mM) (pH 6.6) at $37^{\circ} \mathrm{C}^{18}$. The buffer was supplemented with about $12 \mu \mathrm{M}-\mathrm{Pg} 3$-glc. The intestine was washed of its contents during the first $25 \mathrm{~min}$. Effluents were directly collected at the exit of the ileum during the last 5 min of perfusion. Effluent volume was estimated by weighing. Bile was collected throughout the $45 \mathrm{~min}$ of the experiment. At the end of the experiment, blood samples were withdrawn from the mesenteric vein and abdominal aorta into heparinised tubes. Urine present in the bladder was also collected. Perfused solution, effluent, bile, plasma and urine samples were rapidly acidified with $240 \mathrm{~mm}-\mathrm{HCl}$ and stored at $-20^{\circ} \mathrm{C}$ until analysis.

To determine the stability of Pg 3-glc throughout the in situ perfusion experiment (at $37^{\circ} \mathrm{C}, \mathrm{pH} 6 \cdot 6$ ), a sample of the perfused buffer maintained at $37^{\circ} \mathrm{C}$ was collected at the beginning $(\mathrm{t}=0)$, at $\mathrm{t}=25 \mathrm{~min}$ and at the end of the perfusion period $(\mathrm{t}=45 \mathrm{~min})$, and Pg 3-glc was analysed by HPLC after acidification with $240 \mathrm{mM}-\mathrm{HCl}$, as described later. The overall percentage of degradation (2.26 (SEM 0.53) \%; $n$ 6) was calculated by the decrease in $\mathrm{Pg} 3$-glc concentrations between 0 and $45 \mathrm{~min}$. Moreover, anthocyanin degradation was a linear function of time. Thus, the amounts of Pg 3-glc perfused were determined from the mean of $\mathrm{Pg} 3$-glc concentrations in the perfused buffer at $\mathrm{t}=0$ and $\mathrm{t}=45 \mathrm{~min}$.

\section{Sample preparation}

Urine samples were centrifuged at $12000 \mathrm{~g}$ for $5 \mathrm{~min}$ and the supernatant fraction $(80 \mu \mathrm{l})$ was injected and analysed by HPLC as described later.

Anthocyanins present in plasma samples were extracted with a Sep-Pak $\mathrm{C}_{18}$ Plus solid-phase extraction cartridge (Waters, Milford, MA, USA), using Cy 3-glc as internal standard as previously described ${ }^{17}$, and then analysed by HPLC $(60 \mu \mathrm{l})$.

Caecal contents $(0.2 \mathrm{~g})$ were extracted with $1.8 \mathrm{ml}$ water-acetone $(1: 1, \mathrm{v} / \mathrm{v})$ containing $500 \mathrm{mM}-\mathrm{HCl}$, then briefly sonicated and centrifuged for $5 \mathrm{~min}$ at $12000 \mathrm{~g}$ at room temperature. Supernatant fractions were evaporated under an $\mathrm{N}_{2}$ stream to half their initial volume to eliminate the acetone. Finally, aqueous extracts $(60 \mu \mathrm{l})$ were analysed for anthocyanin content as described later.

Stomach contents were centrifuged for $8 \mathrm{~min}$ at $12000 \mathrm{~g}$ at room temperature, then analysed $(20 \mu \mathrm{l})$ by HPLC. Absorption 
through the gastric wall was estimated by the difference between the amount of Pg 3-glc administered into the stomach and the amount recovered at the end of incubation.

After centrifugation for $8 \mathrm{~min}$ at $12000 \mathrm{~g}$, the supernatant fractions of intestinal effluents were analysed $(20 \mu \mathrm{l})$ by HPLC as described later. All the concentrations measured in the effluent samples were corrected by taking into account the intestinal absorption of water. Water absorption was estimated by calculating the difference between effluent flow (estimated by effluent weighing) and perfusion flow $(0.75 \mathrm{ml} / \mathrm{min})$. Absorption through the intestinal barrier was estimated by calculating the difference between the amount of Pg 3-glc administered through the intestinal segment and the amount recovered at the end of the ileal segment. These amounts were determined for the last $5 \mathrm{~min}$ of perfusion. Anthocyanin stability was also taken into account in evaluating intestinal absorption.

\section{High-performance liquid chromatography analysis}

Quantification of anthocyanins was performed by HPLC using a photodiode array detector (DAD 200; Perkin Elmer, Courtabœuf, France) and a UV-visible detector (785A; Perkin Elmer) at $524 \mathrm{~nm}$. Samples were loaded onto a $150 \times 4.6 \mathrm{~mm}$ Hypersil C18-5 $\mu$ column protected by a $10 \times 4 \mathrm{~mm}$ Hypersil C18-5 $\mu$ guard column (Interchim, Montluçon, France) and analysed as previously described ${ }^{16}$.

Strawberry anthocyanins and anthocyanin metabolites were identified by HPLC-electrospray ionisation-tandem MS (HPLC-ESI-MS/MS) analysis. These analyses were performed on a Hewlett-Packard HPLC system equipped with MS/MS detection (API 2000; Applied Biosystem, Les Ulis, France) as previously described ${ }^{14}$. The MS data were collected in multiple reaction monitoring mode by monitoring the transition of parent and product ions specific for each compound, using a dwell time of $0.5 \mathrm{~s}$. Anthocyanins were detected according to the respective $\mathrm{m} / \mathrm{z}$ values of their parent and product ions: pelargonidin (Pg) (271/121); Pg 3-glc (433/271); pelargonidin 3-malonylglucoside (Pg 3-malglc) (519/271); Pg glucuronide (447/271); Pg 3-glc glucuronide (609/271); Cy 3-glc (449/287).

\section{Polyethylene glycol measurements}

Polyethylene glycol, a compound that is not absorbed by the stomach, was added to the gastric buffer. Its concentration in the gastric buffer was determined by the method of Powell \& Malawer ${ }^{19}$. The ratio between the initial concentration and that measured at the end of the experiment reflected the intensity of gastric secretion (gastric volume at the end of the experiment was about $6 \mathrm{ml}$ ). This parameter has to be taken into account in order to obtain the correct concentration of anthocyanins at the end of the experiment.

\section{Data analysis}

Values are given as means with their standard errors. When appropriate, significance of differences between values was determined by an unpaired $t$ test (GraphPad; Instat, San Diego, CA, USA). Values of $P<0.05$ were considered significant.

\section{Results}

\section{'Adapted rat' study}

The strawberry powder used in the present work showed by HPLC analysis three peaks (Fig. 1(a)). Pg 3-glc (peak 3) was the major anthocyanin $(72 \cdot 8 \%)$. Two other anthocyanins were detected and identified by HPLC-ESI-MS/MS. Peak 5 was identified as Pg 3-malglc by detection of the respective parent and product ion pair $(\mathrm{m} / \mathrm{z}, 519 / 271)$ and accounted for $23.6 \%$ of total anthocyanins. Peak 2 was identified as Cy 3-glc ( $\mathrm{m} / \mathrm{z} 449 / 287)$, accounting for only $3.7 \%$ of total anthocyanins. The concentrations of Pg 3-glc, Pg 3-malglc and $\mathrm{Cy} 3$-glc in the diet were respectively $1 \cdot 11,0.36$ and $0.06 \mathrm{mmol} / \mathrm{kg}$ and their consumption $21.4,6.9$ and $1.1 \mu \mathrm{mol} / \mathrm{d}$.

Anthocyanins were analysed in the urine of strawberry-fed rats (Fig. 1(b)). Urine collected directly in the bladder or in the metabolism cages ( $24 \mathrm{~h}$ urine) both presented the same HPLC profile. The urinary HPLC profile showed strawberry anthocyanins as well as metabolites. The presence of intact strawberry anthocyanins, Cy 3-glc (peak 2), Pg 3-glc (peak 3) and Pg 3-malglc (peak 5) was confirmed by HPLC-ESIMS/MS analysis (specific parent and product ions at $\mathrm{m} / \mathrm{z}$ 449/287, 433/271 and 519/271, respectively). Peak 4 was identified as Pg monoglucuronide according to its parent and product ion pair (447/271). Peak 1 displayed a parent and product ion pair at $\mathrm{m} / \mathrm{z} 609 / 271$, suggesting the presence of Pg 3glc monoglucuronide. Evaluation of anthocyanin urinary excretion was only based on Pg derivatives since Cy 3-glc concentration was too low to allow accurate evaluation of its bioavailability. The mean urinary excretion of Pg derivatives over a $24 \mathrm{~h}$ period is presented in Table 1 . A total of about $0 \cdot 16 \%$ of ingested $\mathrm{Pg}$ glycosides was recovered in urine.

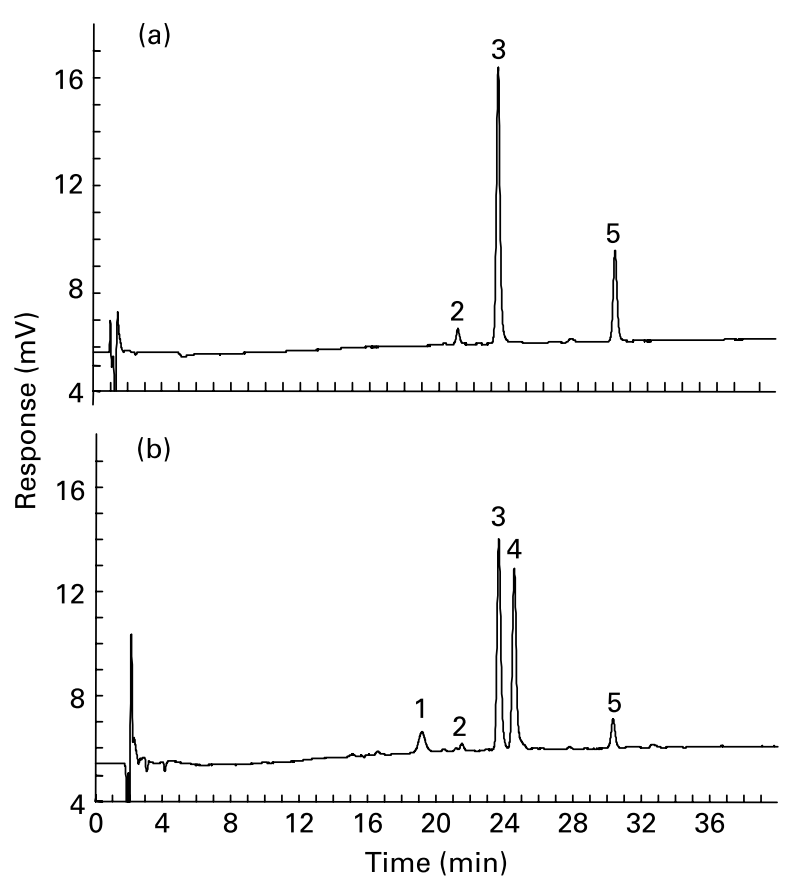

Fig. 1. HPLC chromatograms of strawberry anthocyanins (a) and $24 \mathrm{~h}$ urine from rats fed strawberry powder (b). Detection was performed at $524 \mathrm{~nm}$. Peaks are as follows: (1) pelargonidin 3-glucoside monoglucuronide; (2) cyanidin 3-glucoside; (3) pelargonidin 3-glucoside; (4) pelargonidin monoglucuronide; (5) pelargonidin 3-malonylglucoside. 
Table 1. Urinary excretion of pelargonidin $(\mathrm{Pg})$ derivatives in rats following ingestion of strawberry anthocyanins

(Mean values with their standard errors for eight rats)

\begin{tabular}{lcc}
\hline & \multicolumn{2}{c}{$\begin{array}{c}\text { Urinary excretion (nmol } \\
\text { Cg 3-glc equivalents/24h) }\end{array}$} \\
\cline { 2 - 3 } \cline { 2 - 3 } Compound* & Mean & SEM \\
\hline (1) Pg 3-glc monoglucuronide & $2 \cdot 39$ & 0.15 \\
(3) Pg 3-glc & 21.0 & 1.8 \\
(4) Pg monoglucuronide & 19.1 & 2.1 \\
(5) Pg 3-malglc & 2.97 & 0.33 \\
Total Pg derivatives & 45.4 & 4.0 \\
\hline
\end{tabular}

Pg 3-glc, pelargonidin 3-glucoside; Pg 3-malglc, pelargonidin 3-malonylglucoside. * Numbers refer to the order of elution after HPLC (see Fig. 1(b)).

†Equates to 0.163 (SEM 0.013 ) \% of the ingested amount.

The HPLC analysis of plasma from strawberry-fed rats showed the presence of two anthocyanins identified as $\mathrm{Pg}$ 3-glc and Pg monoglucuronide by HPLC-ESI-MS/MS $(\mathrm{m} / \mathrm{z}$ $433 / 271$ and 447/271, respectively). At the time of killing, i.e. $3 \mathrm{~h}$ after the beginning of the last meal, total plasma anthocyanin concentration was low (48.1 (SEM 5.1) nM). Plasma concentration of $\mathrm{Pg}$ glucuronide was significantly higher than plasma concentration of Pg 3-glc (respectively 29.0 (SEM 3.5) nM and 19.1 (SEM 1.9) nM; $P<0.01$ ).

Analysis of the caecal contents collected $3 \mathrm{~h}$ after the beginning of the last meal showed the presence of the three strawberry anthocyanins (Cy 3-glc, Pg 3-glc and Pg 3-malglc) as well as that of low amounts of Pg (Fig. 2).

\section{In situ gastric administration}

Pg 3-glc (61.0 (SEM 0.4) nmol; $n$ 6) was infused in situ in the rat stomach. Analysis of the stomach content $30 \mathrm{~min}$ after infusion showed an absorption of 14.1 (SEM 1.0) nmol (23.1 (SEM 1.6) \%). No metabolites of Pg 3-glc were observed in

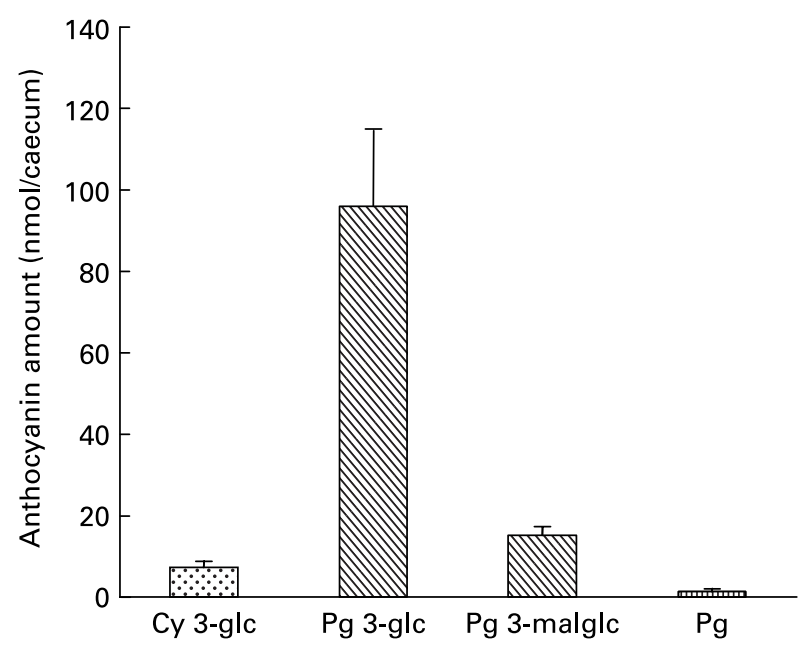

Fig. 2. Anthocyanin amount in total caecal contents of rats fed strawberry anthocyanins collected $3 \mathrm{~h}$ after the beginning of the last meal. Values are means with their standard errors $(n 8)$. Cy 3-glc, cyanidin 3-glucoside; $\mathrm{Pg}$ 3-glc, pelargonidin 3-glucoside; Pg 3-malglc, pelargonidin 3-malonylglucoside; $\mathrm{Pg}$, pelargonidin. the stomach contents. HPLC analysis of pooled urine samples treated by solid-phase extraction revealed the presence of small amounts of Pg 3-glc (Fig. 3(a)).

\section{In situ intestinal perfusion}

Pg 3-glc was also perfused in situ in the small intestine of rats. The HPLC profile of effluents was similar to that of the perfused solution. After perfusion of 50.6 (SEM 4.3) nmol Pg 3-glc ( $n$ 6), 11.9 (SEM 1.5) nmol (23.5 (SEM 2.1) \%) Pg 3 -glc was absorbed from the intestine during the last $5 \mathrm{~min}$ of perfusion. HPLC analysis of urine (Fig. 3(b)) and of plasma collected from the mesenteric vein revealed the presence of Pg 3-glc and Pg monoglucuronide.

\section{Discussion}

The aim of the present study was to evaluate the absorption, metabolism and urinary excretion of strawberry anthocyanins (Pg 3-glc) and compare the results with those previously obtained on blackberry anthocyanins $(\mathrm{Cy} 3 \text {-glc })^{16}$ in order to better understand the influence of aglycone structure on anthocyanin urinary excretion. Metabolism and urinary excretion of strawberry anthocyanins were studied in rats fed for $8 \mathrm{~d}$ with a diet enriched with a lyophilised strawberry powder. The strawberry powder contained mainly Pg 3-glc (about $73 \%$ ). An acylated derivative of Pg 3-glc (Pg 3-malglc, about 24\%) as well as a small amount of Cy 3 -glc $(<4 \%)$ were also present as previously reported ${ }^{20-22}$. Rats ingested about $14 \mathrm{mg}$ anthocyanins/d. This intake corresponds to about a $280 \mathrm{mg} / \mathrm{d}$ intake in human consumers, an amount corresponding to one to two servings of red fruits or berries ${ }^{3}$.

Intact Pg glycosides (Pg 3-glc and Pg 3-malglc) were recovered in urine together with glucuronidated metabolites such as Pg monoglucuronide and Pg 3-glc monoglucuronide.

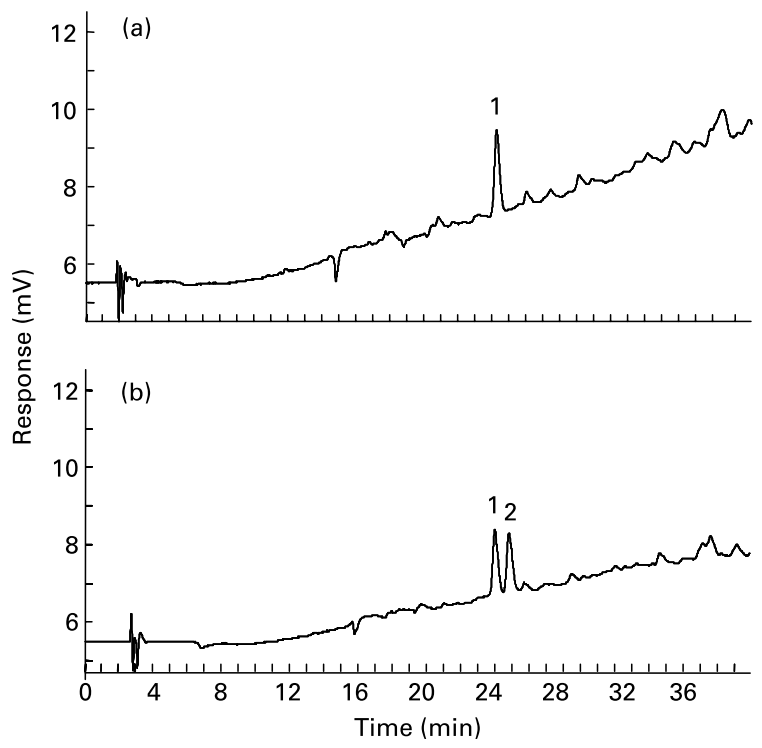

Fig. 3. HPLC chromatograms of urine collected from the bladder after in situ gastric infusion (a) and after in situ intestinal perfusion (b) of pelargonidin 3-glucoside. Detection was performed at $524 \mathrm{~nm}$. Peaks are as follows: (1) pelargonidin 3-glucoside; (2) pelargonidin monoglucuronide. 
The amount of Pg glucuronide excreted was close to that of Pg 3 -glc. This relatively high proportion of glucuronidated anthocyanidin seems to be characteristic of Pg. Indeed, in rats, glucuronide metabolites were only detected in very small amounts in urine after Cy 3-glc feeding ${ }^{23,24}$ and no glucuronides were produced after delphinidin 3-glucoside administration $^{25}$. Pg glucosides were more glucuronidated than cyanidin glycosides in rats, pigs and human subjects ${ }^{14,15,23,24,26,27}$. El Mohsen et al. ${ }^{28}$ have recently identified $\mathrm{Pg}$ glucuronide in plasma and tissues after oral administration into rats with the aglycone Pg. In previous human studies, we have shown that Pg glucuronides were the main strawberry anthocyanin metabolites in urine ( $\mathrm{Pg}$ glucuronide urinary excretion was about 25-fold higher than that of $\mathrm{Pg} \mathrm{3-glc)}$ whereas anthocyanidin glucuronide urinary excretion was only 5-fold higher than that of Cy 3-glc after blackberry feeding $^{14,15}$. Pg has only one hydroxyl group on the B ring. It thus cannot be methylated and may be more available for glucuronidation than other anthocyanins such as Cy 3-glc.

The level of urinary excretion of strawberry anthocyanin metabolites $(0.16 \%$ of the amount ingested) was of the same order of magnitude as previously reported in rats for other anthocyanins ${ }^{16,24,29,30}$ and lower than reported in human subjects or weanling pigs after Pg 3-glc ingestion ${ }^{14,26}$. On the other hand, in human subjects, urinary excretion of anthocyanin metabolites was higher after $\mathrm{Pg} 3$-glc ingestion $(1.8 \%)$ than after that of Cy 3 -glc $(0 \cdot 16 \%)^{14,15}$. This 10 -fold higher urinary excretion of $\mathrm{Pg}$ derivatives as compared with those of cyanidins observed in human subjects may result in part from a very high level of $\mathrm{Pg}$ anthocyanin glucuronidation since the main strawberry anthocyanin metabolite in human urine was a $\mathrm{Pg}$ glucuronide that accounted for $83 \%$ of total urinary metabolites. Moreover the extent of anthocyanin glucuronidation seems higher in man than in rats ${ }^{14,15,24}$.

At $3 \mathrm{~h}$ after the beginning of the last meal, plasma anthocyanin levels were very low. Food consumption was spread over a period of $8 \mathrm{~h}$ and anthocyanins were thus slowly ingested. Such a slow ingestion as well as a rapid elimination ${ }^{31,32}$ probably resulted in low plasma concentrations. Moreover, plasma $\mathrm{Pg}$ glucuronide concentration was significantly higher (about 1.5-fold) than that of Pg 3-glc. Such a difference did not appear in urine. So, it could be hypothesised that Pg glucuronide is distributed to various organs in a higher proportion than Pg 3-glc and less excreted into urine.

Analysis of anthocyanins in the caecal contents revealed the presence of strawberry anthocyanins as well as the aglycone $\mathrm{Pg}$, in agreement with some of our previous results on rats fed various fruits rich in anthocyanins ${ }^{16,29,30}$. As Pg was not present in the strawberry powder, its presence in the caecum probably results from the hydrolysis of anthocyanins by microflora glycosidases. The instability of anthocyanidins at a physiological $\mathrm{pH}$ (near neutrality) was probably responsible for the low Pg content in the caecum, and Pg was probably rapidly transformed to non-coloured and/or degradation products, as recently suggested ${ }^{30,33}$. The low recovery of anthocyanins could also result from adaptation of the microflora to the anthocyanin degradation during the $8 \mathrm{~d}$ of the diet, as previously shown in rats adapted to flavanone-enriched $\operatorname{diets}^{34}$. The proportion of anthocyanin glycosides in the caecum slightly differed from that of the strawberry powder. Proportions of $\mathrm{Pg} \mathrm{3-glc}$ and $\mathrm{Pg}$ 3-malglc related to total anthocyanins were 73 and $24 \%$ in strawberry, respectively. These proportions became 80 and $12 \%$ in the caecal contents, respectively. Acylated Pg 3-glc could be less stable at caecal $\mathrm{pH}$ or more sensitive to enzymic degradation by microflora than non-acylated Pg 3-glc as previously suggested ${ }^{29}$. Moreover, the degradation of Pg 3-malglc by microflora could lead to the formation of Pg 3-glc. Indeed, it has been shown that human faecal microflora were able to hydrolyse acylated groups from acylated anthocyanins ${ }^{33}$.

To gain further insight into the behaviour of strawberry anthocyanins, we investigated $\mathrm{Pg} 3$-glc absorption in the stomach and intestine using low, physiological anthocyanin amounts. Gastric absorption was evaluated after direct administration of Pg 3-glc (about $61 \mathrm{nmol}$ ) into the rat stomach using an in situ gastric administration model ${ }^{17}$. A high proportion (about $23 \%$ ) of $\mathrm{Pg} \mathrm{3-glc}$ was rapidly absorbed from the stomach. Pg 3-glc absorption level was close to that previously reported for various anthocyanin monoglucosides (Cy 3-glc, malvidin 3-glucoside) under the same conditions ${ }^{17}$. Gastric absorption of anthocyanin monoglucosides does not appear to be influenced by the aglycone moiety. No anthocyanins other than Pg 3-glc were detected in urine. So, in accordance with previous studies ${ }^{17,24}$, anthocyanins were absorbed through the gastric wall without modification. The mechanism of anthocyanin permeation in this organ remains unknown but Passamonti et al. ${ }^{35}$ suggested that bilitranslocase, which is an organic anion carrier expressed in the gastric epithelium, could be involved in the gastric absorption of anthocyanins. The absorption and further elimination of Pg 3-glc occurred very quickly since it was recovered in urine only $30 \mathrm{~min}$ after the beginning of the experiment.

Intestinal anthocyanin absorption was also investigated using in situ intestinal (jejuno-ileal) perfusion. A high proportion of Pg 3-glc (about 24\%) is also absorbed from the small intestine. The extent of intestinal absorption is similar to that of Cy 3-glc (about 22\%), as previously reported using the same model ${ }^{18}$. We had showed that the aglycone structure influences the anthocyanin intestinal absorption, the methylated anthocyanin glucosides (malvidin 3-glucoside, petunidin 3 -glucoside) being less easily absorbed than the non-methylated Cy $3-\mathrm{glc}^{18}$. However, the number of free hydroxyl groups on the B ring did not seem to influence intestinal absorption. The absorption and further metabolism of Pg 3glc occurred very quickly, since native glucoside as well as glucuronidated Pg were recovered in plasma and urine only $45 \mathrm{~min}$ after the beginning of the experiment. Pg glucuronide could be formed during the intestinal absorption process. Indeed, UDPglucuronosyltransferase activity is present in the small intestine and intestinal formation of cyanidin glucuronides has been recently reported ${ }^{24,36}$. Taken as a whole, these results raise the question of anthocyanin tissue distribution and their possible transformation after absorption. Indeed, despite a significant absorption in both the stomach and small intestine, only a very small proportion of ingested anthocyanins was recovered in urine and plasma. The present study focused only on anthocyanin metabolites having an anthocyanin skeleton and being thus detected at $524 \mathrm{~nm}$. However, anthocyanin chemistry is complex, and a large part of the absorbed anthocyanins could thus be metabolised to non-coloured forms and/or degradation products due to their chemical instability at physiological $\mathrm{pH}$, and thereby escape detection under usual conditions. 
In conclusion, the present study showed that significant amounts of Pg 3-glc were rapidly absorbed from both stomach and small intestine, similarly to Cy 3-glc. However, Pg 3-glc was glucuronidated to a larger extent than Cy 3-glc. These results highlight the influence of the aglycone structure on anthocyanin metabolism.

\section{References}

1. Clifford MN (2000) Anthocyanins - nature, occurrence and dietary burden. J Sci Food Agric 80, 1063-1072.

2. Kühnau J (1976) The flavonoids. A class of semi-essential food components: their role in human nutrition. World Rev Nutr Diet 24, 117-191.

3. Wu X, Beecher GR, Holden JM, Haytowitz DB, Gebhardt SE \& Prior RL (2006) Concentrations of anthocyanins in common foods in the United States and estimation of normal consumption. J Agric Food Chem 54, 4069-4075.

4. Linseisen J, Radtke J \& Wolfram G (1997) Flavonoid intake of adults in a Bavarian subgroup of the national food consumption survey (article in German). Z Ernahrungswiss 36, 403-412.

5. Kong J-M, Chia L-S, Goh N-K, Chia T-F \& Brouillard R (2003) Analysis and biological activities of anthocyanins. Phytochemistry 64, 923-933.

6. Galvano F, La Fauci L, Lazzarino G, Fogliano V, Ritieni A, Ciappellano S, Battistini NC, Tavazzi B \& Galvano G (2004) Cyanidins: metabolism and biological properties. J Nutr Biochem 15, 2-11.

7. Cooke D, Steward WP, Gescher AJ \& Marczylo T (2005) Anthocyans from fruits and vegetables - does bright colour signal cancer chemopreventive activity? Eur J Cancer 41, 1931-1940.

8. Youdim KA, McDonald J, Kalt W \& Joseph JA (2002) Potential role of dietary flavonoids in reducing microvascular endothelium vulnerability to oxidative and inflammatory insults. J Nutr Biochem 13, 282-288.

9. Wang J \& Mazza G (2002) Effects of anthocyanins and other phenolic compounds on the production of tumor necrosis factor $\alpha$ in LPS/IFN- $\gamma$-activated RAW 264.7 macrophages. J Agric Food Chem 50, 4183-4189.

10. Renaud S \& de Lorgeril M (1992) Wine, alcohol, platelets, and the French paradox for coronary heart disease. Lancet 339, $1523-1526$

11. Heo HJ \& Lee CY (2005) Strawberry and its anthocyanins reduce oxidative stress-induced apoptosis in $\mathrm{PC} 12$ cells. J Agric Food Chem 53, 1984-1989.

12. Kahkonen MP \& Heinonen M (2003) Antioxidant activity of anthocyanins and their aglycons. J Agric Food Chem 51, $628-633$.

13. Wang SY \& Lin HS (2000) Antioxidant activity in fruits and leaves of blackberry, raspberry, and strawberry varies with cultivar and developmental stage. J Agric Food Chem 48, 140-146.

14. Felgines C, Talavéra S, Gonthier MP, Texier O, Scalbert A, Lamaison JL \& Rémésy C (2003) Strawberry anthocyanins are recovered in urine as glucuro- and sulfoconjugates in humans. J Nutr 133, 1296-1301.

15. Felgines $\mathrm{C}$, Talavéra S, Texier O, Gil-Izquierdo A, Lamaison JL \& Rémésy C (2005) Blackberry anthocyanins are mainly recovered from urine as methylated and glucuronidated conjugates in humans. J Agric Food Chem 53, 7721-7727.

16. Felgines C, Texier O, Besson C, Fraisse D, Lamaison JL \& Rémésy C (2002) Blackberry anthocyanins are slightly bioavailable in rats. $J$ Nutr 132, 1249-1253.

17. Talavéra S, Felgines C, Texier O, Besson C, Lamaison JL \& Rémésy C (2003) Anthocyanins are efficiently absorbed from the stomach in anesthetized rats. J Nutr 133, 4178-4182.
18. Talavéra S, Felgines C, Texier O, Besson C, Manach C, Lamaison JL \& Rémésy C (2004) Anthocyanins are efficiently absorbed from the small intestine in rats. J Nutr 134, 2275-2279.

19. Powell DW \& Malawer SJ (1968) Relationship between water and solute transport from isosmotic solutions by rat intestine in vivo. Am J Physiol 215, 49-55.

20. Aaby K, Skrede G \& Wrolstad RE (2005) Phenolic composition and antioxidant activities in flesh and achenes of strawberries (Fragaria ananassa). J Agric Food Chem 53, 4032-4040.

21. Wu X \& Prior RL (2005) Systematic identification and characterization of anthocyanins by HPLC-ESI-MS/MS in common foods in the United States: fruits and berries. J Agric Food Chem 53, 2589-2599.

22. da Silva FL, Escribano-Bailon MT, Perez Alonso JJ, RivasGonzalo JC \& Santos-Buelga C (2007) Anthocyanin pigments in strawberry. LWT - Food Sci Technol 40, 374-382.

23. Ichiyanagi T, Shida Y, Rahman MM, Hatano Y \& Konishi T (2005) Extended glucuronidation is another major path of cyanidin 3-O- $\beta$-D-glucopyranoside metabolism in rats. $J$ Agric Food Chem 53, 7312-7319.

24. Talavéra S, Felgines C, Texier O, Besson C, Gil-Izquierdo A, Lamaison JL \& Rémésy C (2005) Anthocyanin metabolism in rats and their distribution to digestive area, kidney, and brain. J Agric Food Chem 53, 3902-3908.

25. Ichiyanagi T, Rahman MM, Kashiwada Y, Ikeshiro Y, Shida Y, Hatano $\mathrm{Y}$, Matsumoto $\mathrm{H}$, Hirayama M, Tsuda T \& Konishi T (2004) Absorption and metabolism of delphinidin 3-O- $\beta$-D-glucopyranoside in rats. Free Radic Biol Med 36, 930-937.

26. Wu X, Pittman HE III \& Prior RL (2004) Pelargonidin is absorbed and metabolized differently than cyanidin after marionberry consumption in pigs. J Nutr 134, 2603-2610.

27. Kay CD, Mazza GJ \& Holub BJ (2005) Anthocyanins exist in the circulation primarily as metabolites in adult men. $J$ Nutr 135, 2582-2588.

28. El Mohsen MA, Marks J, Kuhnle G, Moore K, Debnam E, Kaila Srai S, Rice-Evans C \& Spencer JP (2006) Absorption, tissue distribution and excretion of pelargonidin and its metabolites following oral administration to rats. Br J Nutr 95, 51-58.

29. Felgines C, Talavéra S, Texier O, Besson C, Fogliano V, Lamaison JL, Fauci L, Galvano G, Rémésy C \& Galvano F (2006) Absorption and metabolism of red orange juice anthocyanins in rats. Br J Nutr 95, 898-904.

30. Talavéra S, Felgines C, Texier O, Besson C, Mazur A, Lamaison JL \& Rémésy C (2006) Bioavailability of a bilberry anthocyanin extract and its impact on plasma antioxidant capacity in rats. J Sci Food Agric 86, 90-97.

31. Bitsch I, Janssen M, Netzel M, Strass G \& Frank T (2004) Bioavailability of anthocyanidin-3-glycosides following consumption of elderberry extract and blackcurrant juice. Int $J$ Clin Pharmacol Ther 42, 293-300.

32. Tsuda T, Horio F \& Osawa T (1999) Absorption and metabolism of cyanidin $3-O-\beta-d$-glucoside in rats. FEBS Lett 449 , $179-182$

33. Fleschhut J, Kratzer F, Rechkemmer G \& Kulling SE (2006) Stability and biotransformation of various dietary anthocyanins in vitro. Eur J Nutr 45, 7-18.

34. Felgines C, Texier O, Morand C, Manach C, Scalbert A, Régerat F \& Rémésy C (2000) Bioavailability of the flavanone naringenin and its glycosides in rats. Am $J$ Physiol 279, G1148-G1154.

35. Passamonti S, Vrhovsek U \& Mattivi F (2002) The interaction of anthocyanins with bilitranslocase. Biochem Biophys Res Commun 296, 631-636.

36. Ichiyanagi $\mathrm{T}$, Shida $\mathrm{Y}$, Rahman MM, Hatano $\mathrm{Y}$, Matsumoto H, Hirayama M \& Konishi T (2005) Metabolic pathway of cyanidin 3-O- $\beta$-D-glucopyranoside in rats. J Agric Food Chem 53, $145-150$. 